\title{
Establiments comercials i fires en la poesia de Pau Puig
}

\author{
Commercial establishments and fairs in the poetry of Pau Puig
}

\author{
Maria-Rosa Serra Milà \\ mrosa.serra@cobdc.org \\ ILLC - Universitat de Girona
}

\begin{abstract}
Resum: Entre l'obra en vers de Pau Puig trobem una vintena de composicions dedicades a botigues i fondes barcelonines, la majoria relacionada amb petits altars o capelles que s'hi havien instal lat. Fidel al seu estil, Puig hi manté un to desenfadat i utilitza gran quantitat de locucions i de jocs de paraules referents a les activitats comercials de cada establiment. Més satíric amb els costums llibertins de l'època es mostra l'autor en El Sarrabal de la ciudad de Barcelona para el año 1792, obra en prosa castellana que parodia els calendaris o pronòstics i on va anomenant les festes, processons, saraus i fires que se celebraven a Barcelona al llarg de l'any. En alguns casos incorpora poemes en català i en castellà per il lustrar les celebracions. Aquí ens centrarem en els poemes referits a les fires.
\end{abstract}

Paraules clau: Pau Puig, segle XVIII, botigues, fires, poesia humorística

Abstract: Within Pau Puig's works we can find some twenty pieces related to shops and inns in Barcelona. Most of them refer to small shrines or chapels located there. Pau Puig, compliant with his style, shows an easygoing tone and uses a wide range of collocations and puns when mentioning the commercial activity of each establishment. Puig is much more satyrical about the libertine mores of his time in his work El Sarrabal de la ciudad de Barcelona para el año 1792 (a kind of What's On in Barcelona in 1792). This work is written in Spanish prose and makes fun of the calendars and forecasts. He also shows a list of public holidays, religious processions, parties and fairs that take place in Barcelona througout the year. In some cases the author includes poems in Spanish and Catalan to enlighten the celebrations. This paper will focus on the poems related to fairs.

Keywords: Pau Puig, XVIII century, shops, fairs, humorous poetry 


\section{Pau Puig, un clergue burleta}

Pau Puig (1722-Barcelona 1798) era clergue regular menor del convent barceloní de Sant Sebastià. Va ostentar diversos càrrecs religiosos, però destacà sobretot com a predicador. Pel que en diuen els seus contemporanis, els seus sermons eren tan amens i enginyosos que tenia nombrosos seguidors i li encomanaven sovint de fer prèdiques a la catedral o en diverses esglésies de Barcelona i de moltes altres ciutats de Catalunya. Nou dels seus sermons es van imprimir a l’època (Serra 2012: 5-19).

A més dels sermons, Pau Puig és autor, com a mínim, d'uns nou-cents poemes (en català i en castellà), de quatre obres teatrals (una comèdia de sants i dos entremesos en català, i un entremès en castellà) i d'una extensa obra en prosa castellana, però que incorpora poemes en català i castellà.

Si una característica defineix tota l'obra de Pau Puig és el seu to desenfadat. Fins i tot en els poemes de tema religiós, la broma i el joc de paraules hi són presents, de vegades gairebé acostant-se a la irreverència o a la grolleria.

El llenguatge literari és ric, de lèxic entenedor, i no són rares ni les paraules vulgars ni els cultismes. Com correspon a la moda de l'època, el seu català conté freqüents castellanismes lèxics. Però allò que destaca en l'obra de Puig és l'ús constant de modismes i frases fetes, i també de recursos literaris, especialment jocs de paraules, metàfores, hipèrboles i paradoxes, moltes vegades utilitzats amb doble sentit i freqüentment amb un dels sentits picant o eròtic. Pel que fa a la versificació, l'estrofa preferida de Puig és la dècima, encara que també va escriure sonets, octaves, seguidilles, quartetes, poemes amb eco o en romanç. De vegades, utilitza rimes difícils, en una mostra més d'agudesa i enginy.

Com correspon al seu estat, una bona part dels poemes de Pau Puig és de tema religiós: sovint es tracta de poemes d'encàrrec, per commemorar una beatificació, l'estrena d'un altar o bé una altra festivitat religiosa. Tanmateix, una quantitat considerable de la seva obra conrea temes anecdòtics o humorístics i ens presenta una extensa galeria de personatges populars i d'escenes pintoresques, com el cas d'un escolà murri que robava ciris i els revenia, una vídua que tenia un amant amb una cama de fusta, una coneguda actriu teatral que havia infantat malgrat ser soltera, la baralla entre una monja i un sagristà, o la visita d'un clergue molt prim i golafre. Poemes, tots ells, que tenien la finalitat de divertir i fer somriure el lector.

A l'època, Pau Puig va ser un personatge conegut i la seva poesia força llegida i divulgada de forma manuscrita, com ho demostra el fet que hem trobat poemes seus en divuit manuscrits diferents, la majoria pertanyents a persones afeccionades a la poesia, que reunien peces pròpies i d'altres autors. 


\section{Establiments comercials barcelonins}

Entre els poemes de Pau Puig en trobem una vintena de dedicats a establiments comercials, que generalment fan referència a imatges o capelles que s'hi havien col locat $i$ també al ludint elogiosament als serveis que s'hi oferien. Aquests poemes es penjaven a les parets de la botiga o al carrer perquè els clients i passavolants poguessin llegir-los.

Els poemes XXXIX i XLII ${ }^{1}$ estan dedicats a una barberia. El primer, compost per vuit dècimes, acaba amb el cognom Sabà, que entenem que era el del propietari, i és escrit per felicitar el Nadal a la clientela i alhora fer publicitat dels diversos serveis de l'establiment, on, com en totes les barberies de l'època, a més d'afaitar i tallar els cabells s'aplicaven sangoneres, es feien sagnies, s'arrencaven queixals i s'extirpaven grans i furóncols. Per exemple, la quarta estrofa diu:

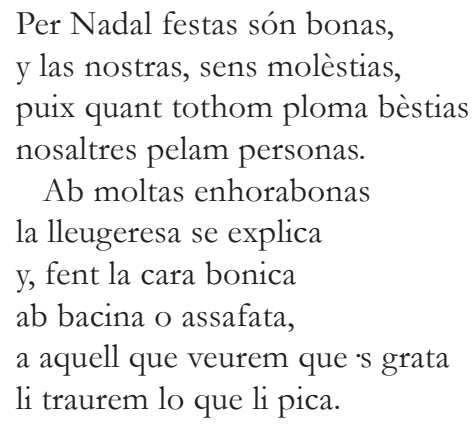

El poema XLII, que probablement va ser escrit per a la mateixa barberia que l'anterior, celebra la diada dels patrons dels barbers i dels metges: els sants Cosme i Damià. A diferència dels barbers, que no es van poder independitzar del col legi de cirurgians, els perruquers - que tenien una clientela de categoria social superior i sovint atenien a domicili- s'erigiren en gremi propi el 1773 i tenien com a patró sant Onofre (Curet 1982: 189-190; Carrera Pujal 1951: II, 378).

Els poemes LXXI i LXXII són poemes d'encàrrec per a un flequer, que havia guarnit una capelleta en honor de Llorenç de Brindisi, per commemorar-ne la beatificació, l’any 1783.

A l'època era freqüent bastir altars i capelles al carrer per commemorar beatificacions o altres festivitats religioses. Sovint eren els botiguers els qui es feien càrrec de la construcció, però també les famílies poderoses solien contribuir al lluïment de les festes, com ens explica el Baró de Maldà al Calaix de sastre: "en la iglésia de la Mercè se fa un altar nou d'escultura, i dorat que ja és, per col locar-s'hi lo cos dins de sa urna de santa Maria de Cervelló o del Socors, que està vui dia interinament lo sepulcre i imatge de la santa barcelonesa en la capella frente a esta, en lo crucero, a expenses de casa Medinaceli» (Boixareu 1988: 72).

1 Els números dels poemes fan referència a l'edició crítica de l'obra catalana de Pau Puig (Serra 2012). Tot els textos de Puig citats en el present treball provenen d'aquesta mateixa edició. 
Comas (1985: 243) reprodueix una composició de Francesc Martí, d’època i de temàtica molt semblants a les de Pau Puig, però òbviament de to i estil diferents: «Per acompanyar la tosca idea de l'altar tot fet de llegums que féu composar en sa casa lo forner de la Portaferrissa amb motiu de la beatificació del B. Llorenç de Brindis». Les dues dècimes elogien l'art de formar un altar amb «requisits de pobra gent/ i pastos de animals».

A continuació, Comas (1985: 244) cita uns poemes anònims també col locats en una botiga, amb motiu de la mateixa beatificació. D'intenció clarament satírica, aprofiten el lloc de naixement del beat per bromejar sobre els brindis i l'embriaguesa: «En les festes del B. Llorenç de Brindis, de Barcelona, en la casa d'en Beco, junt a una parada de botelles de vàrios licors, se llegien les següents poesies... ».

Duran i Sanpere (1973: 659-660) explica que aquestes capelles improvisades situades a les façanes de les cases eren visitades per un públic molt més nombrós que el que assistia als temples i que, a força de reproduir-se cada any en el mateix paratge, adquirien categoria de permanència $i$ en alguns casos fins i tot donaven lloc a la creació de confraries.

També el poema XLV està dedicat a una capelleta, en aquest cas instal lada a la botiga d'un sabater. Per això Pau Puig, a més de recalcar la puresa de Maria -única persona no tacada pel pecat original-, utilitza modismes referents al calçat:

A María Santíssima en su concepción, cuia imagen estaba en la capilla de la casa de un zapatero. Décima

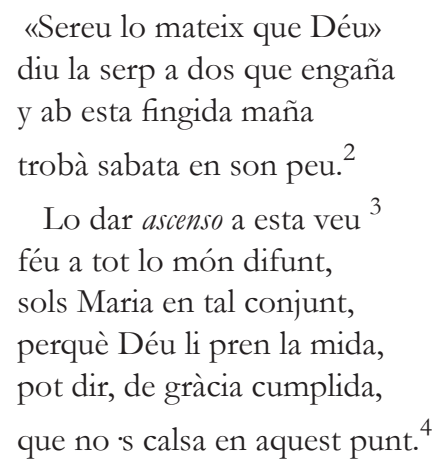

Alguns poemes reflecteixen la situació política del moment, com el poema LXXIV, que es congratula per la firma de la pau amb Anglaterra, després de quatre anys de conflictes. Aquesta guerra (17791783) causà un gran trastorn a l'economia catalana, per tal com el bloqueig marítim dels anglesos tallà el comerç exterior de Catalunya, impedí l'arribada de matèries primeres per a la indústria i

2 «Trobar sabata a son peu» vol dir 'trobar allò que hom cercava, o les conseqüències d'allò que hom ha fet' (DCVB).

3 dar ascenso : expressió castellana que significa 'fer cas, donar crèdit o autoritat'.

4 «Calçar en un punt» significa 'necessitar un número determinat de sabata' i, de forma figurada, 'pertànyer a un grup o categoria' (DCVB). 
deixà sense feina molts menestrals i jornalers. I com que el poema s'havia de posar en una fusteria, Pau Puig no s'està d'utilitzar locucions referents a la fusta:

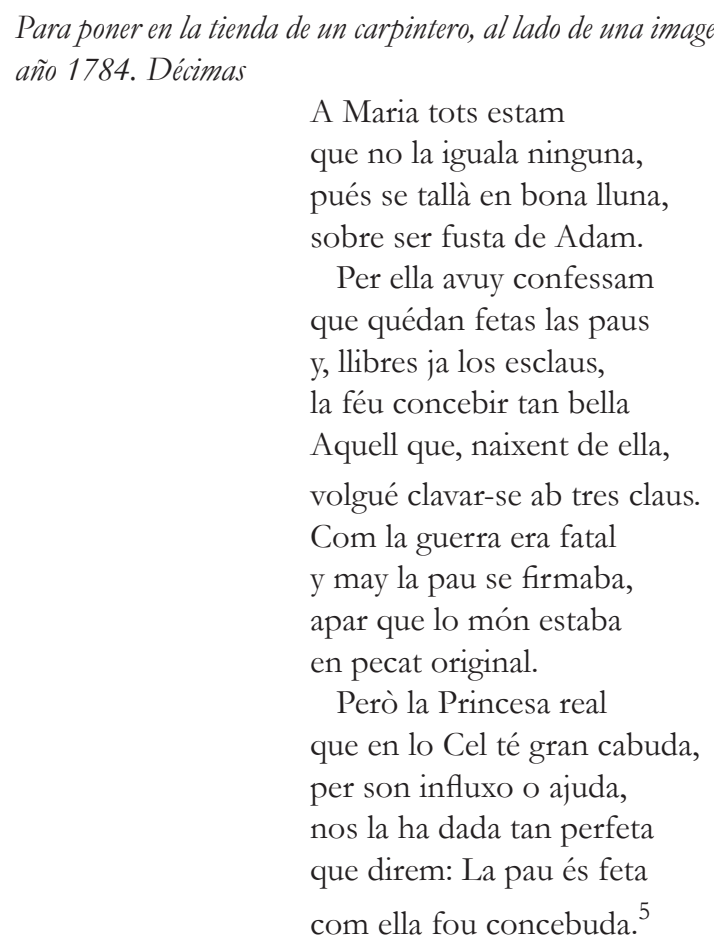

També el poema LXVIII es fa ressò de les circumstàncies polítiques i militars del moment. Aquí Puig ironitza amb la paradoxa que, mentre es produeix el bombardeig d'Alger per part de les tropes espanyoles, un moro sigui el senyal o símbol emblemàtic d'una botiga barcelonina de teixits i cintes que s'utilitzaven per a guarnir, sobretot, la indumentària militar i religiosa.

L'atac de què fa esment el poema és un dels efectuats durant l'any 1783 contra la plaça d'Alger. Antoni Barceló, com a tinent general de les tropes espanyoles, va ordenar vuit bombardeigs que van destruir més de quatre-centes cases de la població, encara que va haver-se de retirar en venir els mesos freds de l'hivern. ${ }^{6}$

La botiga a què fa referència el poema probablement és la del galoner Vives, situada al carrer de la Bòria, de la qual ens parla Fra Josep Torrentó en la Relacion de los solemnes aparatos, magníficos, afectuosos festejos y pomposas celebridades... (Comas 1985: 249):

5 La pau es va firmar el dia de la Concepció.

6 Els èxits militars i el valor d'Antoni Barceló (Ciutat de Mallorca 1717-1797) el varen fer objecte de mitificació, prova de la qual són els poemes reproduits en els fullets 9355 i 9628 del Fons Bonsoms de la Biblioteca de Catalunya i diversos romanços i corrandes populars, com la que diu: «Si el rey de España tuviera / cuatro como Barceló / Gibraltar fuera de España / que de los ingleses no». 
En casa de un galonero pusieron un altar hecho de cintas y galones, el que passaban los tres santos dominicos: Domingo, Jacinto y Raymundo de Peñafort. ${ }^{7} Y$ aviendo puesto un moro para indicio de la casa, quando sucedía el bombardeo de Argel por Don Antonio Barceló, lo animó el author con las siguientes décimas ${ }^{8}$

\author{
Per Domingo en festa rica \\ y per passos no comuns \\ veig una casa dilluns \\ que treballa en dominica. \\ La feyna en ella se explica \\ ab adornos molt perfets, \\ publicant fins las parets \\ que ab las més vivas unions \\ aquí seran los canons ${ }^{10}$ \\ quant allí seran los pets. ${ }^{11}$ \\ Preveyent lo gran treball \\ que té Argel en Barceló, \\ prench per menor aflicció \\ el que $\mathrm{m}$ passin Bòria vall. ${ }^{12}$ \\ De aygua he passat lo tall \\ quant tres patrons soberans \\ favoreixen a dos mans, \\ atrayent ab tal decoro \\ que fassa la crida un moro \\ y diga: «Devots christians».
}

\begin{abstract}
7 Sant Domingo de Guzmán (Caleruega, Burgos, 1170 - Bolonya, 1221) va ser el fundador de l'orde dels Dominics. Sant Jacint (Breslau, Silèsia, 1185 - Cracòvia, 1257) va entrar al nou orde dels Dominics o Predicadors el 1216 i va fundar molts convents, a Polònia sobretot. Sant Raimon de Penyafort (Penyafort, Vilafranca, cap a 1175 - 1275) el 1210 va anar a Bolonya a estudiar Dret i a fer de professor. Allà va conèixer sant Domingo de Guzmán i als 47 anys prengué l'hàbit dominicà. Confessor de Jaume I, que en parla sovint en la seva crònica, s'hi va barallar sovint per la vida llicenciosa del monarca. També va intervenir en la fundació de l'orde de la Mercè.
\end{abstract}

8 Segons Curet (1982: II, 14): «En moltes botigues era present a l'aparador un ninot, personatge estàtic que semblava presidir i vigilar la parada».

9 Pel context sembla que aquest vers signifiqui que la botiga treballa en diumenge. Però el que vol dir és que la botiga treballa sota l'advocació dels tres sants dominics.

10 Joc de significats de la paraula canons: 'armes de foc' i 'estoig de guardar agulles'.

11 És a dir, els canons i els ornaments militars es troben a la botiga barcelonina, però és a Alger on s'utilitzen.

12 «Anar Bòria avall»: 'càstig que es donava antigament a certs delinqüents en la ciutat de Barcelona i que consistia a fer-los recórrer el carrer de la Bòria i altres vies, cavalcant en un ase i nus de mig cos en amunt, i ésser assotats per la mà del botxí en cada cantonada' (DCVB). El fet que aquí s'esmenti el carrer de la Bòria referma la suposició que es tracta de la botiga del galoner Vives. 


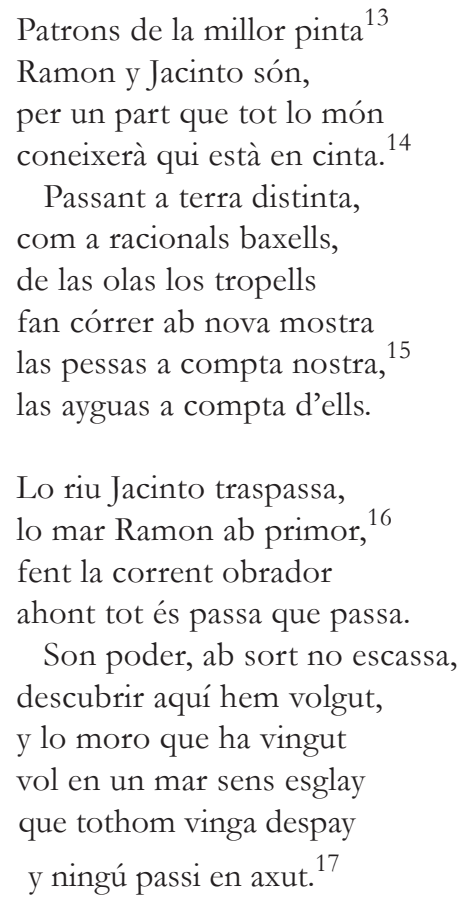

13 També es devien vendre pintes a la botiga del galoner.

14 Joc de paraules que fa referència als guarniments i a la mercaderia de la botiga i també a «encinta» o embarassada. Sant Ramon Nonat i sant Jacint són sants invocats per als parts.

15 Mostres i peces són altres elements propis de la botiga.

16 Un dels miracles més coneguts de Sant Raimon de Penyafort va ser navegar des de Mallorca a Barcelona a bord d'una capa d'abric, la meitat de la qual feia la funció de casc de vaixell, i l'altra meitat, de vela. Conta Ribadeneyra (1751: I, 121-122) que el rei Jaume I no volia que el seu confessor marxés de Mallorca, i va prohibir a tots els patrons de vaixell que el portessin a Barcelona. Ignorant això sant Raimon, després de rebre negatives de tots els mariners del port, va agafar la capa del seu company, va llançar-la a la mar, va pujar-hi, i posà el bordó a manera de màstil, subjectant un tros de capa perquè fes de vela. La navegació va durar tan sols sis hores i va ser ben calmada i segura, segons el seu company de viatge, que estava tan astorat com tots els qui van contemplar l'escena a un port i a l'altre.

Sant Jacint va fer un miracle molt semblant: havia d'anar a la ciutat de Visograd, a la Rússia meridional, a predicar. Aquesta ciutat està situada sobre un riu de gran cabal i, com que el sant no tenia vaixell per travessar-lo, va treure's la capa, la va estendre sobre el riu, i ell i els seus companys van poder passar-hi com si fos una barca. I quan sant Jacint va arribar de Chio, fugint dels tàrtars, amb el Santíssim Sagrament en una mà i la imatge de la Mare de Déu en l'altra, va arribar al riu Baristenes i tampoc no va trobar cap embarcació per conduir-lo a l'altra riba. En aquesta ocasió, va passar el riu a peu, per sobre l'aigua, sense mullar-se ni la sola de la sabata, i darrere seu van passar també tots els frares que l'acompanyaven. I diu Ribadeneyra (1751: II, 495) que a les aigües del riu van quedar les marques dels seus passos, i que encara avui es veuen.

17 Possible referència a la dita «carrer mullat, calaix eixut», que significa que quan plou els botiguers venen poc. També es podria interpretar «eixut» amb el sentit de 'magre, sense diners'. Aquí el moro de la botiga vol que la gent vingui i que compri.

SCRIPTA, Revista internacional de literatura i cultura medieval i moderna, núm. 10/desembre 2017/pp. 257-272 ISSN: 2340 - 4841 doi:10.7203/SCRIPTA.10.11082 
Dedicades a la barcelonina fonda dels Tres Reis - situada al carrer del Malcuinat, amb sortida al pla de Palau número 10- trobem deu composicions breus en català (poemes XIII, LIX, LX, i CIIICIX) i tres en castellà entre l'obra de Pau Puig.

Aquesta fonda és l'establiment que hem pogut documentar millor de tots els que tracta la poesia del nostre autor. L'esmenten Amades (1984: II, 837), Curet (1982: 299), Caballé i Clos (1946: I; 36, 4648), Carrera Pujal (1951: II, 360), Miguelsanz i Arnalot (2009: 41, 55, 60), les pàgines web de Bàguena (2016) i de Fígols Company (2015) i, sobretot, Villar (2008: 69-72), que li dedica tot un apartat.

Segons Villar, l'hostal ja existia al segle XVI, però al 1772 es va inaugurar un cafè a sota, que es va configurar com a local de negocis, aprofitant la proximitat del port. Al cafè dels Tres Reis s'anunciaven les arribades i les sortides de les embarcacions, es despatxaven passatges i es facturaven mercaderies. També es posaven a la venda al cafè mateix productes diversos arribats en els vaixells, cosa que s'anunciava en el Diario Evangélico, Histórico-Político, publicació que només es venia al Cafè i a cinc establiments més de la ciutat.

La decoració de l'establiment no era luxosa, per bé que no hi faltaven ornaments i un punt de distinció: taules de fusta de pi pintades, bancs i cadires, pocs miralls i quadres, i una llumenera penjada al sostre. Les taules del cafè dels Tres Reis tenien escalfetes, una mena de brasers de llautó, on sempre hi havia foc encès per facilitar l'encesa de les pipes i dels cigarrets que fumaven els clients. Durant gran part del segle XIX la fonda i el cafè van continuar existint i n'era el propietari Marc Francesc Català, capità d'infanteria retirat, que va demanar llicències d'obres el 1816, el 1823 i el 1827. Fins al 1857 està documentada aquesta fonda.

Tots els poemes de Pau Puig dedicats a la fonda dels Tres Reis eren destinats a ser penjats per les parets, prop de l'altar que els propietaris havien col locat amb motiu de la festivitat del Corpus i durant tota la vuitada. A més del missatge religiós, tots al ludeixen a la bona taula de la fonda, de la qual aconsellen gaudir després de la processó. Suposem que aquests poemes responien a un encàrrec o a una deferència de l'autor envers aquest establiment a causa del veïnatge, ja que el convent de Sant Sebastià i la fonda eren ben a prop.

Creiem que els deu poemes es van escriure en tres anys diferents, perquè les decoracions que ens detallen els encapçalaments dels poemes difereixen una mica les unes de les altres. En el poema XIII, que és una octava, l'encapçalament diu: «En la octava del Corpus, en una de las fondas, llamada de los Tres Reyes, se puso un altar en que estaba pintada la Cena. Sobre la cabeza de Christo, esta letra: "Pinguis est panis". A un lado, los tres Reyes y esta letra: "Probebit delicias regibus". A otro lado, san Thomás de Aquino y esta letra: "In hac mensa novi regis" ». ${ }^{18}$ Com podem comprovar, els missatges són mig religiosos i mig publicitaris.

18 Les frases en llatí signifiquen: «Menjar en abundància»; «Tastareu requisits propis de reis»; «En aquesta taula d'un nou rei». 
El poema LIX, format per dues dècimes, ens descriu en el davantal una decoració amb un nou element $\mathrm{i}$ un nou personatge: «En una de las fondas, que es la de los Tres Reyes, se bizo un altar en que estaba el Arca del Testamento, y David baylando delante de ella». L'encapçalament del poema LX ens diu: «En el dia de la octava de Corpus, añadieron al altar la Cena». Com que en la primera de les dues dècimes de què es compon el poema s'anomena l'Arca, suposem que van afegir el Sant Sopar a l'anterior altar, és a dir que aquests dos poemes correspondrien al mateix any.

El davantal dels poemes CIII-CIX explica: «En el dia de la octava de Corpus, en la fonda o hosteria de la Fonda dels Tres Reys, pintats sobre la porta que va a Bethlem, posaren devant de dit quadro a sant Thomàs ab la custòdia en la mà. Ha eixit esta glosa, que està aprobada per los calificadors del Sant Offici». Pel contingut dels diferents poemes (una octava i sis dècimes), deduïm que la imatge de sant Tomàs d'Aquino es feia moure davant de la pintura dels Reis.

Alguns poemes d'aquesta sèrie, com el poema $\mathrm{CV}$, poden fer pensar que la fonda donava menjar gratuïtament, però creiem que es tracta d'una metàfora de l'aliment espiritual que és el cos de Crist:

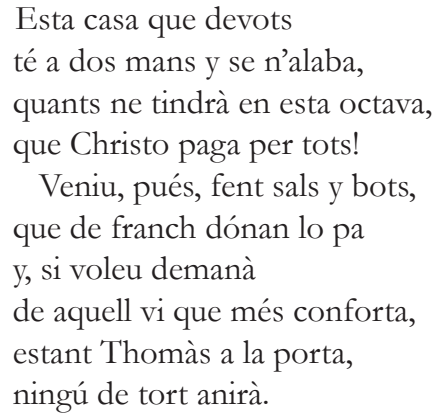

En el poema CVIII la fonda dels Tres Reis ja no es presenta com a empresa tan desinteressada, sinó que es diu que fan fortuna amb l'abundant clientela i que «tenen amor als pagants»:

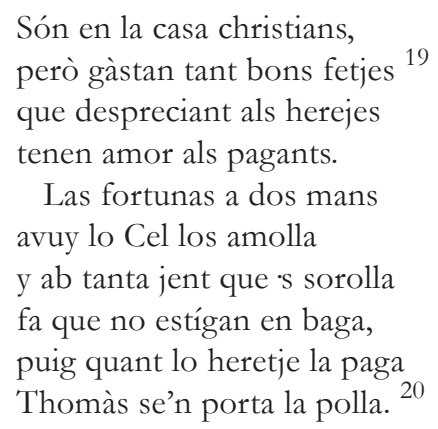

19 L'expressió «tenir bon fetge» significa 'tenir molta calma, no perdre la tranquil litat'.

20 Sant Tomàs s'emporta el millor plat, que és el triomf sobre l’heretgia. 


\section{Fires per donar i per vendre}

El Sarrabal de la ciudad de Barcelona para el año 1792 és una peça humorística en prosa castellana on Pau Puig fa una paròdia dels calendaris o pronòstics, tan populars durant els segles XVII, XVIII i XIX. Aquests calendaris tenien unes seccions fixes, com ara les festes religioses movibles, els còmputs cronològics (on es calculava quants anys feia des de la creació del món, del diluvi universal, etc.), el judici de l'any -on es vaticinava la meteorologia, la producció agrícola, o la situació econòmica i política-, o el calendari pròpiament dit, amb els dies, els sants, les celebracions, les llunes, etc. En El Sarrabal de la ciudad de Barcelona para el año 1792, Pau Puig segueix l'ordre de les seccions fixes dels almanacs, però aquí el «Cómputo cronológico» es torna «cuerno-lógico» i els pronòstics sobre l'any són obvietats: «Sucederá en este año todo lo que Dios quisiere, que lo mismo fue los pasados y acontecerá en los sucesivos». En el calendari, s'aprofiten els noms dels sants o els costums del dia per fer-ne bromes: «JJulio] 1. San Casto: Apenas conozco uno de este nombre». Igualment en clau d'humor són els poemes en castellà o en català que il lustren algunes celebracions o costums populars.

Aquesta obreta va tenir dues edicions pòstumes, els anys 1820 i 1835, on no es feia constar el nom de l'autor, sinó només el pseudònim humorístic, «Don Verídico Claro». Hem pogut saber que l'autor era Pau Puig gràcies a un manuscrit que la hi atribueix (Serra Milà 2002: 283, 305; Serra 2012: 61-63, 391).

En el repàs que fa de les festes, processons, saraus i celebracions de tot tipus que es feien a Barcelona, Puig ens anomena una quantitat considerable de fires, i ho amenitza amb alguns poemes. En les seccions fixes que precedeixen el calendari pròpiament dit, la de «Ferias» ens adverteix que moltes celebracions religioses són, de fet, fires de festeigs i d'intercanvis eròtics: «Ferias. Deben entenderse por tales los cursos de las procesiones en el octavario del Corpus y Semana Santa, fiestas mayores, comedias, bayles, novenarios, passeos, tertulias, etc., en donde bay géneros que, quando no se venden, se empeñan a carta de gracia. Gracias a los fundadores de tales obras pías». Aquí, però, ens limitarem a les fires comercials, com la dels tortells de Sant Antoni:

[Enero] 17. San Antonio Abad. Quartos menguantes en los bolsillos de los petimetres ${ }^{21}$ que concurren en esta feria, con motivo de los repetidos y expuestos encuentros.

Las mulas que advirtieres
más encintadas ${ }^{22}$
muerden y tiran coces
por viciadas.

21 Puig fa sovint crítica dels «petimetres» i dels «currutacos», joves presumits que fan la cort a dones, sovint casades, $\mathrm{i}$ també d'aquestes dones, que corresponen als seus galanteigs.

22 El dia de Sant Antoni, patró dels animals, es feia (i es fa) la cavalcada dels Tres Tombs, on els traginers, bastaixos, arriers i llogaters de mules portaven les bèsties, ben guarnides, a beneir. El poema té un doble sentit, també aplicable a les dones. 


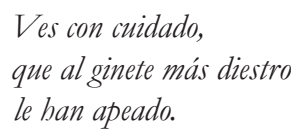

Com hem dit, Pau Puig vivia al convent de Sant Sebastià, situat darrere del palau de Llotja, al lloc on actualment hi ha la plaça d'Antoni López, i al costat de les voltes dels Encants. El convent s'havia edificat al costat de la capella de Sant Sebastià, capella que l'Ajuntament de Barcelona havia fet construir entre els anys 1507 i 1509, arran d'una forta epidèmia de pesta. Cada any el dia de Sant Sebastià una important comitiva de l'Ajuntament anava a la capella per agrair la protecció del Sant. El Calaix de sastre ho detalla així: «Dia 20 de gener, Sant Fabià i Sant Agustí, màrtirs. Anaren en professó des de la catedral a la iglésia de Sant Sebastià a dos quarts de deu del matí los dos il lustres cossos, capítol i ajuntament, a cantar un ofici -votat de la ciutat per la pesta-com se acostuma en tots los anys. (...) Torrat sota les voltes dels Encants» (Boixareu 1988: 156).

En el Sarrabal, Puig aprofita per ironitzar sobre els objectes -i les persones- de segona mà que s'oferien als Encants:

[Enero] 20. San Sebastián. Feria en los encantes, y lo dicho, dicho.

$$
\begin{aligned}
& \text { Aqui nos venden por nuevos } \\
& \text { muebles que fueron usados. } \\
& \text { Ab! Quantos conozco yo } \\
& \text { que les sucedió otro tanto. }
\end{aligned}
$$

També el dia de Sant Pau es feia una fira de tortells torrats pels voltants de l'església de Sant Pau del Camp, però segons Amades (1950-1956: I, 593) només en menjava la gent benestant, i en canvi les classes més humils menjaven tortell per sant Antoni:

[Enero] 25. La conversión de san Pablo. Rua, empellones, torrat tortelly lo que se paga. Dézima

$$
\begin{aligned}
& \text { Quantas per menjar tortell } \\
& \text { empeñaren moltas cosas, } \\
& \text { y n’i hagué de tan golosas } \\
& \text { que fins vengueren la pell! } \\
& \text { Com las moscas a la mel } \\
& \text { acuden, y són molt pocas } \\
& \text { las que del tortell las socas } \\
& \text { arràncan sens mol treball, } \\
& \text { perquè càvan tan avall } \\
& \text { que arríban fins a las mocas. }
\end{aligned}
$$

23 Segurament, es refereix a núvies que no eren verges.

24 Tant socas com mocas pot tenir el sentit de 'les parts interiors o baixes', i en conseqüència, un sentit eròtic, que avança ja el quart vers. 
Un dels molts costums de la vigília de Sant Joan era fer soroll. Totes les cobles i orquestres de la ciutat sortien a tocar pels carrers i places, i també es formaven colles improvisades de jovent que, sense saber música, tocaven el pandero, la bandúrria, la guitarra, els ferrets, etc. A Barcelona es parava una fira a la Riera de Sant Joan, on es venien herbes, llepolies i xiulets. Era costum que tota la mainada es firés amb un xiulet. Els joves enamorats regalaven coques i herbes aromàtiques a la seva xicota, i elles al seu torn obsequiaven amb un xiulet el seu estimat. El so molestós i antipàtic dels xiulets de vidre era la nota típica d'aquest dia (Amades 1950-1956: IV, 178-179):

[Junio] 24. San Juan Bautista: Feria en que los muchachos empiezan a rompernos la cabeza con sus silvatos.

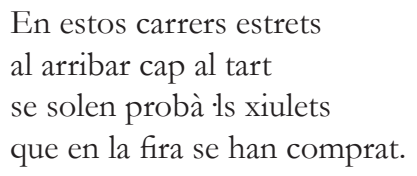

Pocs dies després se celebrava una fira al carrer de Sant Pere Més Baix i era semblant a la fira de Sant Joan, però no tan animada i concorreguda com aquesta (Amades 1950-1956: IV, 276). Pau Puig s'admira de l'encant de les noies que s'hi passegen amb els vestits prims d'estiu, que deixen endevinar les formes del cos:

[Junio] 29. San Pedro: Otra feria por el mismo estilo.

$$
\begin{aligned}
& \text { Quinas miñonas tan sanas } \\
& \text { en est barri trobaràs! } \\
& \text { Aquell deyx, aquell garvàs, } \\
& \text { aquells culets de indianas } \\
& \text { que diuhen: «dilluns, dimars» }^{25} \\
& \text { no t'òbran, xarrich, las ganas? }
\end{aligned}
$$

El barri del Regomir feia la seva festa per Sant Cristòfol. Pels seus carrers es feia una fira, que era la primera en què es venien ventalls, i cada any l'enamorat comprava a l'estimada el ventall que ella triava.

La següent dècima es fa ressò dels costums llibertins i adúlters de l'època. La frase feta que acaba el poema de Pau Puig té el seu origen en un altre costum d'aquest dia, que consistia a dir als nens que avui podrien veure la imatge del sant en la posició que cada un volgués: agenollat, dret, assegut, etc. Els petits entenien que la imatge es mouria al seu gust, però davant la decepció dels infants els grans els deien que eren ells els qui podien canviar de posició sense deixar de veure el sant (Amades 1950-1956: IV, 474-498):

25 L'expressió «dilluns, dimars» deu voler imitar el moviment oscil lant del darrere de les noies.

26 xarrich: «xerric», 'vailet, bordegàs'.

SCRIPTA, Revista internacional de literatura i cultura medieval i moderna, núm. 10/desembre 2017/pp. 257-272 ISSN: 2340 - 4841 doi:10.7203/SCRIPTA.10.11082 
[Julio] 10. San Christóval. Quarto menguante; revuelto en agua, cossi de pomas en el Regomí, Cadena, feria, etc. Décima

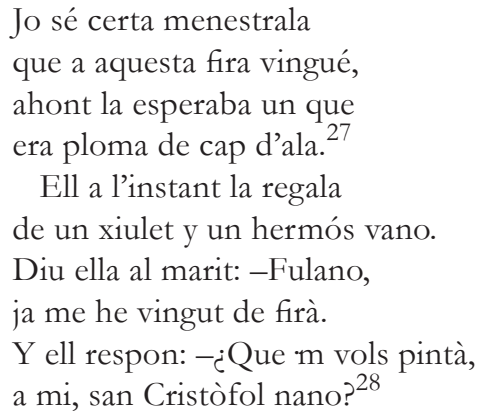

Per la Mare de Déu del Carme se celebrava la festa major del barri del Raval. Era costum que les fadrines estrenessin un vestit estampat, de colors ben vius i que la gent els donés poms de flors. Després d'anar a visitar la Mare de Déu i de demanar-li que les fes casar aviat, les donzelles passejaven fira amunt i fira avall, esperançades de trobar promès. La veu popular deia que d'aquesta fira n'havien sortit molts enamoraments, i per això se l'anomenava la «fira dels marits» (Amades 1950-1956: IV, 504-507). Aquí Pau Puig, després d'admirar la bellesa i gràcia de les noies, crea un contrast de regust barroc, quan n'evoca la defecació:

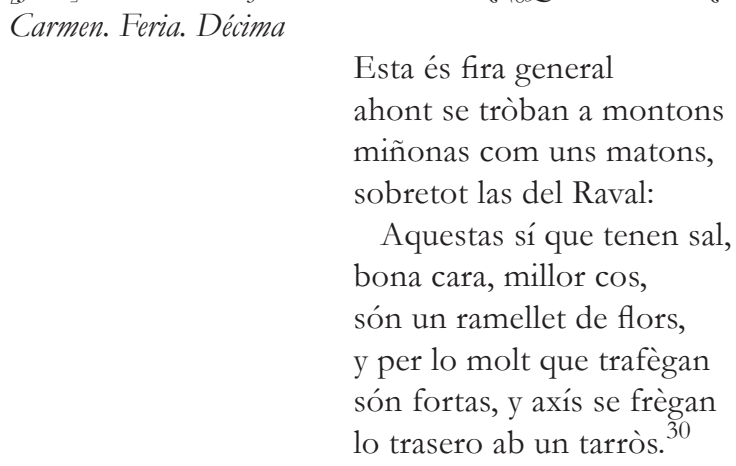

També el dia de Sant Jaume es feia una fira, sobretot de parades de melons, pels voltants de la vella església de Sant Jaume, situada on avui hi ha la plaça del mateix nom. I també les fadrines demanaven al sant que els trobés casador ben aviat (Amades 1950-1956: IV, 585-621; Caballé i Clos 1946: 175):

27 ploma de cap d'ala: 'persona eminent o de qualitats recomanables'.

28 «Pintar sant Cristòfol nano»: 'pretendre fer creure allò que no és'.

29 El 16 de juliol s'havia esdevingut el triomf de les armes cristianes contra les islàmiques a les Navas de Tolosa. Per això a la plaça del Pedró es venien coques amb una creu trepitjant la mitja lluna (Amades 1950-1956: IV, 513).

30 Segons testimonis orals, l'expressió «eixugar-se el cul amb un terrós» vol dir 'semblar molt fi i educat, però no serho tant com es vol aparentar'. 


\author{
[Julio] 25. San Jayme. Feria.
}

Quantas n'i ha en esta fira que a lo que 's veu tenen trassa de ser-ne, de tot bon cor, Sant Jaume y la carabassa. ${ }^{31}$

Per Tots Sants era costum visitar el fossar de l'Hospital o Corralet, al carrer del Carme. En aquest carrer, i també en d'altres, es muntava una fira de castanyes i panellets, que la gent comprava en tornar de visitar el fossar. També era habitual durant aquest dia anar a visitar els boigs i els malalts de l'hospital (Amades 1950-1956: V, 610-615). La dècima del Sarrabal, a més d'ironitzar en l'encapçalament sobre els fills bords, ens presenta una visita un xic interessada, i que rep un moc per resposta:

[Noviembre] 1. Todos los santos: Quarto creciente en pitimetres: revuelto en cafés, panallets, castañas, malvasia, ayres pestiferos nacidos de los Paises Bajos, que apestaran la circumferencia. En esta tarde, mucha concurrencia de gentes en el Hospital, donde piden limosna muchos hijos a sus padres sin conocerlos. Alpasarpor la Convalecencia. Décima

$$
\begin{aligned}
& \text { Aquí don Francisco Estoitx, } \\
& \text { gran tocador de bandola, } \\
& \text { vingué a veure una mussola } \\
& \text { que algun temps li feya goitx. } \\
& \text { Ell era un poch boquiroytx, } \\
& \text { atormentàban-lo las moscas, } \\
& \text { y estant-ne mitx a las foscas, } \\
& \text { a l'apretar-li'n la mà, } \\
& \text { li diu : -No t faltarà pa. } \\
& \text { Y ella respon: -Ni a tu crostas. }
\end{aligned}
$$

El dia de sant Tomàs apòstol començaven les fires més importants de tot l'any, que duraven fins a la vigília de Nadal. A l'Esplanada i a la Rambla era on es venia l'aviram. Era costum que els senyors anessin a passejar per l'Esplanada amb llurs robes més bones i tants criats com podien. Allà compraven els millors caps d'aviram i els feien portar pels criats. La població humil hi acudia per admirar el luxe dels rics i la mainada hi anava en colles per veure els indiots $i$ altres bèsties no gaire corrents durant la resta de l'any (Amades 1950-1956: V, 6-18). En els dos darrers versos, Pau Puig fa un joc de paraules dels que tant li agraden, amb el be o xai, que es la menja tradicional de Pasqua, i el gall, que es menja per Nadal:

31 Els pelegrins que anaven a Sant Jaume de Galícia portaven una carabassa plena d'aigua i penjada al bordó. La dita «ser sant Jaume i la carabassa» s'aplica a dues persones de mida desigual que sempre van juntes (Amades 1980: 77).

32 bandola: 'espècie de guitarra de quatre cordes'.

33 mussola: 'dona beneita'. 
[Deciembre] 21. Santo Thomàs: Very creher. Estamos en un tiempo en que se crehe abún lo que no se ve, porque por los antecedentes se presume. Luna nueva sin estrenar: Revuelto en porchs, pavos, gallos, pollas, gallinas, pollos, capones, truxas, farciment y demás con que se alborotan los muchachos en esta feria:

$$
\begin{aligned}
& \text { Allarga, Payrot, la bossa } \\
& \text { y llueyx-ne lo censal; }{ }^{35} \\
& \text { qui per Pasqua és para-bé, }{ }^{36} \\
& \text { ara ha de ser para-gall. }
\end{aligned}
$$

Quan el Calaix de sastre ens parla d'aquesta fira ens explica també la funció religiosa de la tarda, a càrrec justament del nostre autor (Boixareu 1988: 155):

\begin{abstract}
Dia 21 de desembre, Sant Tomàs Apòstol. Fira de Barcelona, com en tots los anys, de tot gènero de manufactures i demés mercaderies. En est any, respecte de fer bon temps, arribaren molts galls i polles [...]. Als preus la compra dels indiots, sis o set pessetes cada peça; arrenglantse les manades dels indiots en tota l'Esplanada, i també los tocinos que van entrant, per estar embarassada la plaça dels Porcs, o necessitar-se per la nova fàbrica de l'Aduana.
\end{abstract}

En tal tarda de 21 de desembre se cantà rosari ab la capella de música de la catedral en la col legiata de Santa Anna, fent l'explicació dels misteris gloriosos, en català, lo pare Puig, de Sant Sebastià.

Com hem vist, Pau Puig combinava l'activitat de predicador amb la d'escriptor i poeta, i en totes dues mostrava una simpatia i un bon humor que no el van abandonar ni en els seus últims moments. Segons ens conta Torres Amat (1836: 507): «Hasta pocas horas antes de morir conservó su genio festivo y dijo: "Hasta ahora he sido el P. Puig, ya comienzo a ser el P. Put, y luego seré el P. Fuig" (...)».

I en les composicions del nostre autor referents a establiments comercials o a fires hem pogut observar la funció pràctica de la poesia i la seva profunda vinculació a la societat. Aquests poemes menors, de consum efímer, no tenien més pretensió que contribuir al lluïment de les festes o obtenir un somriure del lector, però sens dubte en podem apreciar la frescor, l'enginy i l'habilitat poètica.

34 Payrot: «Peirot», nom propi d’home, diminutiu de Pere. Familiarment, era el nom que es donava als creditors o als deutes pendents.

35 censal: 'pensió, paga'.

36 para-bé: catalanització del mot castellà parabien, que significa 'enhorabona, felicitació'. També joc de paraules amb el significat de be, 'xai', que enllaçarà amb el vers següent.

37 para-gall: paraula inventada per paralel lisme amb para-bé i que fa referència al gall que es menja per Nadal. 


\section{Bibliografia}

Amades, J. (1950-1956) Costumari català: el curs de l'any, I i IV, Barcelona, Salvat, 5 vol. (1980) Refranys personals, Barcelona, Selecta.

(1984) Històries i llegendes de Barcelona: passejades pels carrers de la ciutat vella, Barcelona, Edicions 62, 2 vol.

Boixareu, R. (ed.) (1988 [1a ed. 1987]) Rafael Amat i de Cortada, Baró de Maldà, Calaix de sastre I: 1769-1791, 2a ed., Barcelona, Curial. (volums?)

Bàguena, N. (2016). «Els canvis alimentaris en el període en què Barcelona va passar de ser una ciutat emmurallada a una ciutat en expansió», dins el blog Cuina del 19 [en xarxa].

$\leq$ https://cuinadel19.wordpress.com/2016/03/12/els-cafes-a-la-barcelona-del-xix > [Consulta: 01/06/2017].

Caballé i Clos, T. (1946) Los Viejos cafés de Barcelona, Barcelona, Albón, 2 vol.

Carrera Pujal, J. (1951) La Barcelona del segle XVIII, II, Barcelona, Bosch, 2 vol.

Comas, A. (1985) Història de la Literatura catalana, VI, Barcelona, Ariel, 10 vol.

Curet, F. (1982) Visions barcelonines, II: Botigues, obradors i cases de menjar i beure, Barcelona, Altafulla.

Duran i Sanpere, A. (1973) Barcelona i la seva història, II, Barcelona, Curial, 3 vol.

Fígols Company, C. (2015) Antics hostals de camí ral [en xarxa].

$<$ https://hostals.blogspot.com.es/2015/09/fonda-dels-tres-reis-barcelona.html > [Consulta: 01/06/2017].

Miguelsanz i Arnalot, À. (2009) Barcelona, parada i fonda: l'bostaleria de la ciutat: dels orígens als nostres dies, Barcelona, Labeltur.

Ribadeneyra, P. de (1751) Flos sanctorum de las vidas de los santos, II, Barcelona, Juan Piferrer, 12 vol.

Serra Milà, R. M. (ed.) (2012) Pau Puig, Obra catalana, Barcelona, Barcino.

(2002) «El Sarrabal de la ciudad de Barcelona para el año 1792, una obra de Pau Puig, de publicació pòstuma», Barcelona, Quaderns d'Història, 7 (2002) [Ramon Grau, coord., El segle de l'absolutisme, 1714-1808], pp. 281-305.

Torres Amat, F. (1836) Memorias para ayudar a formar un diccionario crítico de los escritores catalanes, y dar alguna idea de la antigua y moderna literatura de Cataluña, Barcelona, Imprenta de J. Verdaguer.

Villar, P. (2008) La ciutat dels cafès: Barcelona 1750-1880, Barcelona, Ajuntament de Barcelona / La Campana. 